\title{
Abnormal Striatal GABA Transmission in the Mouse Model for the Fragile X Syndrome
}

\author{
Diego Centonze, ${ }^{*}$ Silvia Rossi, Valentina Mercaldo, Ilaria Napoli, Maria Teresa Ciotti, Valentina De Chiara, \\ Alessandra Musella, Chiara Prosperetti, Paolo Calabresi, Giorgio Bernardi, and Claudia Bagni*
}

Background: Structural and functional neuroimaging studies suggest abnormal activity in the striatum of patients with the fragile $X$ syndrome (FXS), the most common form of inherited mental retardation.

\begin{abstract}
Methods: Neurophysiological and immunofluorescence experiments in striatal brain slices. We studied the synaptic transmission in a mouse model for FXS, as well as the subcellular localization of fragile X mental retardation protein (FMRP) and brain cytoplasmic (BC1) RNA in striatal axons.

Results: Our results show that absence of FMRP is associated with apparently normal striatal glutamate-mediated transmission, but abnormal $\gamma$-aminobutyric acid (GABA) transmission. This effect is likely secondary to increased transmitter release from GABAergic nerve terminals. We detected the presence of FMRP in axons of striatal neurons and observed a selective increase in the frequency of spontaneous and miniature inhibitory postsynaptic currents (sIPSCs, mIPSCs) in fmr1-knockout mice. We also observed reduced paired-pulse ratio of evoked IPSCs, a finding that is consistent with the idea that transmitter release probability from striatal GABAergic nerve terminals is higher than normal in these mutants. Finally, we have identified the small noncoding BC1 RNA as a critical coplayer of FMRP in the regulation of striatal synaptic transmission.
\end{abstract}

Conclusions: Understanding the physiologic action of FMRP and the synaptic defects associated with GABA transmission might be useful to design appropriate pharmacologic interventions for FXS.

Key Words: BC1 RNA, electrophysiology, EPSC, fragile X mental retardation protein, $\mathrm{mRNA}$, synaptic plasticity

$\mathrm{T}$ ranscriptional silencing of the fmr1 gene on the $\mathrm{X}$ chromosome causes fragile $\mathrm{X}$ syndrome (FXS), the most common form of inherited mental retardation (1). fmr1 gene encodes the fragile $\mathrm{X}$ mental retardation protein (FMRP), an RNA-binding protein involved in mRNA metabolism in neurons (2,3). Patients with FXS show a spine dysmorphogenesis (2). Dendritic spines are a preferential working location of FMRP in neurons $(2,4)$, but evidence is now accumulating that axons also contain this protein (5-7). These findings raise the possibility that FMRP controls synaptic transmission through pre- and postsynaptic actions.

FMRP mediates its complex activity on synaptic transmission by interacting with specific RNA and protein partners. At least 18 putative FMRP-interacting proteins $(2,4)$ and a plethora of FMRPbinding mRNAs have been identified (8-13). In addition, FMRP can also control synaptic protein translation indirectly by associating with either the small dendritic noncoding brain cytoplasmic (BC1) RNA (12,14), or possibly with microRNAs (15), which act as an "adaptor molecules" between FMRP and its target mRNAs.

Abnormal plasticity of excitatory transmission represents a prominent synaptic alteration described in fmr1 knockout (fmr1-

From the Clinica Neurologica (DC, SR, VDC, AM, CP, GB), Dipartimento di Neuroscienze, Università Tor Vergata; Fondazione Santa Lucia/Centro Europeo per la Ricerca sul Cervello (CERC) (DC, SR, VM, IN, VDC, AM, CP, $\mathrm{PC}, \mathrm{GB}, \mathrm{CB})$; Dipartimento di Biologia (VM, IN, CB), Università Tor Vergata; Consiglio Nazionale delle Ricerche/Centro Europeo per la Ricerca sul Cervello (CERC) (MTC), Rome; and Clinica Neurologia (PC), Università di Perugia, Ospedale Silvestrini, Perugia, Italy.

Address reprint requests to Diego Centonze, M.D., Clinica Neurologica, Dipartimento di Neuroscienze, Università Tor Vergata, Rome, Italy; E-mail: centonze@uniroma2.it.

Received April 5, 2007; revised August 10, 2007; accepted September 12, 2007.
KO) mice (4,16-19), a reliable model of FXS showing, as in the human disorder, macroorchidism, learning deficits, hyperactivity, and dendritic spine abnormalities (2). In this model, the possible parallel alteration of inhibitory GABAergic transmission has also been postulated in morphological, neurochemical, and molecular studies (20-26), but it has never been addressed physiologically.

Several brain imaging studies in humans have established an association between reduced expression of FMRP and morphological and functional abnormalities in the basal ganglia of patients with FXS. Accordingly, FXS patients present frontostriatal deficits and larger striatum than normal, abnormalities that tightly correlate with the severity of the disease (27-33). This evidence suggests synaptic deficits in this brain area, but no study thus far has addressed striatal synaptic functioning in models of FXS.

In this study, we investigated both inhibitory and excitatory synaptic transmission in the striatum of fmr1-KO mice. In this model of FXS, we found enhanced $\gamma$-aminobutyric acid (GABA)mediated synaptic inhibition, secondary to loss of presynaptic FMRP-mediated control of transmitter release. By comparing the neurophysiologic effects of fmr1 KO with those of BC1 RNA KO and those of double fmr1 and BC1 KO, we also identified BC1 RNA as a critical coplayer of FMRP in the regulation of striatal synaptic transmission.

\section{Methods and Materials}

Mice lacking fmr1 (fmr1-KO) (34), BC1 RNA (BC1-KO) (35), and both fmr1 and BC1 (fmr1-BC1-KO) were employed, along with respective age-matched wildtype (WT) counterparts (2-3 months old) for all the experiments. Animals were maintained in light:dark cycles of 12:12 hours and weaned after 21 days. The WT and KO mice used in these experiments were of different background strains: C57BL/6 for fmr1-KO mice, $129 \mathrm{~Sv} / \mathrm{C} 57 \mathrm{BL} / 6$ for $\mathrm{BC} 1-\mathrm{KO}$ and fmr1-BC1-KO. Appropriate matching strains were used as controls. All efforts were made to minimize animal 
suffering and to reduce the number of mice used, in accordance with the European Communities Council Directive of 24 November, 1986 (86/609/EEC).

\section{Generation of fmr1-BC1-KO Mice}

fmr1-KO mice were obtained from Ben Oostra's laboratory (34), and BC1-KO mice were obtained from Jurgen Brosius's laboratory (35). One fmr1-KO female $\left(\mathrm{X}^{-} \mathrm{X}^{-}\right)$was crossed to BC1-KO male $\left(7^{-} 7^{-}\right)$to generate heterozygous female mice for both the fmr1-BC1-KO loci and fmr1-KO male mice heterozygous for BC1-KO locus. These mice $\left(\mathrm{X}^{-} \mathrm{X}^{+} / 7^{-} 7^{+} \mathrm{x} \mathrm{X}^{-} \mathrm{Y} / 7^{-} 7^{+}\right)$ were then crossed to generate the following genotypes: 1$)$ mice lacking $\left(\mathrm{X}^{-} \mathrm{Y} / 7^{+} 7^{+}\right)$or $\left(\mathrm{X}^{-} \mathrm{X}^{-} / 7^{+} 7^{+}\right)$or $\left(\mathrm{X}^{-} \mathrm{Y} / 7^{-} 7^{+}\right)$or $\left(\mathrm{X}^{-} \mathrm{X}^{-} /\right.$ $\left.7^{-} 7^{+}\right)$; 2) mice lacking BC1 RNA $\left(\mathrm{X}^{+} \mathrm{Y} / 7^{-} 7^{-}\right)$or $\left(\mathrm{X}^{+} \mathrm{X}^{+} / 7^{-} 7^{-}\right)$; 3) normal male mice $\left(\mathrm{X}^{+} \mathrm{Y} / 7^{+} 7^{+}\right)$; 4) heterozygous mice for BC1 $\left(\mathrm{X}^{+} \mathrm{Y} / 7^{+} 7^{-}\right)$; 5) heterozygous mice for fmr1 $\left(\mathrm{X}^{-} \mathrm{X}^{+} / 7^{+} 7^{+}\right)$; 6) heterozygous female mice for both fmr1 and BC1 $\left(\mathrm{X}^{-} \mathrm{X}^{+} / 7^{-} 7^{+}\right)$; 7) mice lacking both fmr1 and $\mathrm{BC} 1\left(\mathrm{X}^{-} \mathrm{Y} / 7^{-} 7^{-}\right)$or $\left(\mathrm{X}^{-} \mathrm{X}^{-} /\right.$ $\left.7^{-} 7^{-}\right)$. All mice were genotyped by polymerase chain reaction (PCR) using genomic DNA extracted from the tail. Screening for the presence or absence of the BC1 WT allele was performed using primer BMN176 (5'-GGACAAAGTGGCTCCTCCTG-) and BMN177 5' (-GGAGTATCCGGCATCCTCTG-) to detect the 436 fragment (nt 31094-31530 ID No. AF384675), and screening for the presence or absence of the BC1-KO allele was performed using primer BMN174 5'(-CCCAGCAATGGTGATGAGAC-) and BMN175 5'(-CCTTCTATCGCCTTCTTGACG) to detect the 462 fragment of the mutant allele (nt 28796 ID No. AF384675-NEO cassette). Following an initial cycle at $94^{\circ} \mathrm{C}$ for $5 \mathrm{~min}, 20 \mathrm{PCR}$

A

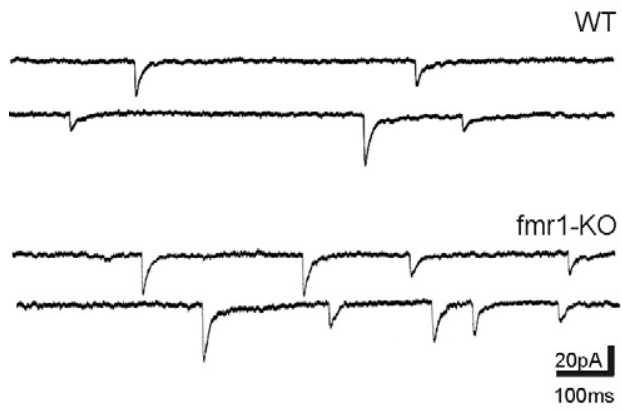

C
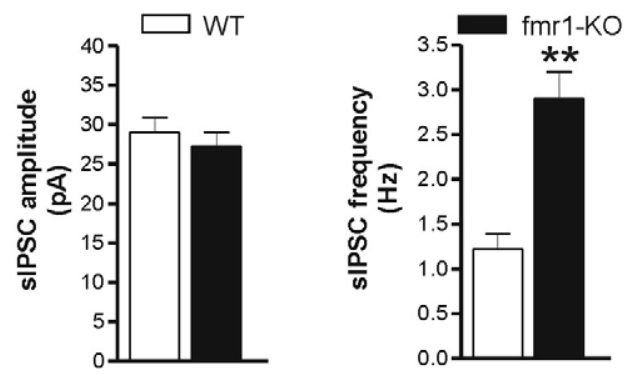

cycles were performed comprising 1 min denaturation at $94^{\circ} \mathrm{C}, 1$ min annealing at $60^{\circ} \mathrm{C}$, and $1 \mathrm{~min}$ extension at $72^{\circ} \mathrm{C}$. The products were electrophoresed on $1.5 \%$ agarose gel. The analysis of fmr1 locus was conducted as previously described (34).

\section{Electrophysiology}

Corticostriatal coronal slices $(200 \mu \mathrm{m})$ were prepared from tissue blocks of the mouse brain with the use of a vibratome $(36,37)$. A single slice was then transferred to a recording chamber and submerged in a continuously flowing Krebs solution $\left(32^{\circ} \mathrm{C}, 2-3 \mathrm{~mL} / \mathrm{min}\right)$ gassed with $95 \% \mathrm{O}_{2}-5 \% \mathrm{CO}_{2}$. The composition of the control solution was (in mmol $/ \mathrm{mL}$ ): $126 \mathrm{NaCl}$, $2.5 \mathrm{KCl}, 1.2 \mathrm{MgCl}_{2}, 1.2 \mathrm{NaH}_{2} \mathrm{PO}_{4}, 2.4 \mathrm{CaCl}_{2}, 11$ Glucose, and 25 $\mathrm{NaHCO}_{3}$.

The striatum could be readily identified under low-power magnification, whereas individual neurons were visualized in situ using a differential interference contrast (Nomarski) optical system. This employed an Olympus BX50WI (Tokyo, Japan) noninverted microscope with $\times 40$ water immersion objective combined with an infrared filter, a monochrome charge-coupled device camera (COHU 4912), and a PC-compatible system for analysis of images and contrast enhancement (WinVision 2000, Delta Sistemi, Italy).

Whole-cell patch clamp recordings were made with borosilicate glass pipettes (1.8 $\mathrm{mm}$ outer diameter; $2-4 \mathrm{M} \Omega$ ), in voltageclamp mode, at the holding potential (HP) of $-80 \mathrm{mV}$. Recording pipettes were advanced toward individual striatal cells in the slice under positive pressure, and on contact, tight G $\Omega$ seals were made by applying negative pressure. The membrane patch was

\section{B}

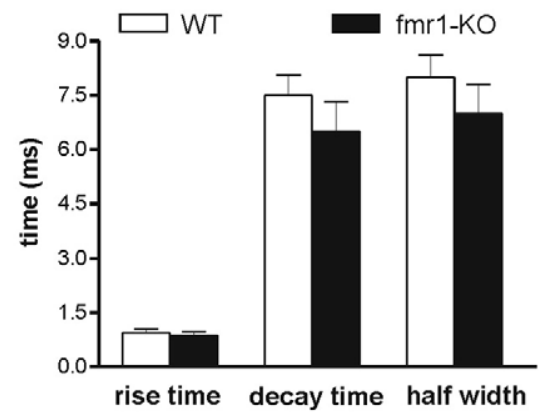

D

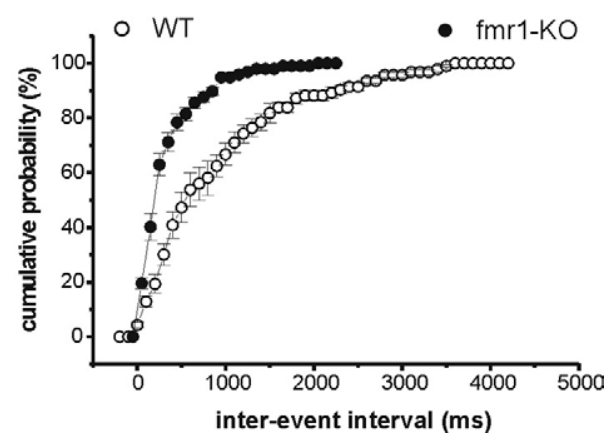

Figure 1. Properties of spontaneous inhibitory postsynaptic currents (sIPSCs) recorded from striatal neurons of wildtype (WT) and fmr1-knockout (KO) mice. (A) Examples of voltage-clamp recordings showing striatal sIPSCs (downward deflections) recorded from WT and fmr1-KO mice. (B) The graph shows that the kinetic properties (rise time, decay time, and half width) of sIPSCs are similar in the two genotypes. (C) The histograms show that the absence of fragile $X$ mental retardation protein remarkably increases the frequency of sIPSCs without altering the mean amplitude of these synaptic events. (D) Cumulative distribution of sIPSC interevent interval recorded from WT and fmr1-KO mice. 
then ruptured by suction and membrane current and potential monitored using an Axopatch 1D patch clamp amplifier (Axon Instruments, Foster City, California). Whole-cell access resistances measured in voltage clamp were in the range of 5-20 M $\Omega$. To detect evoked (eIPSCs), spontaneous (sIPSCs), and miniature GABAA-mediated inhibitory postsynaptic currents (mIPSCs), intraelectrode solution had the following composition $(\mathrm{mM})$ : $\mathrm{CsCl}$ (110), $\mathrm{K}^{+}$-gluconate (30), ethylene glycol-bis ( $\beta$-aminoethyl

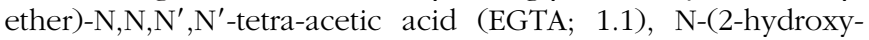
ethyl)-piperazine-N-s-ethanesulfonic acid (HEPES) (10), $\mathrm{CaCl}_{2}$ (0.1), Mg-adenosine triphosphate (Mg-ATP) (4), Na-guanosine triphosphate (GTP) (.3). (+)-5-methyl-10,11-dihydro-5H-dibenzo[a,d]cyclohepten-5, 10-imine maleate (MK-801) $(30 \mu \mathrm{mol} / \mathrm{mL})$ and 6-cyano-7-nitroquinoxaline-2,3-dione (CNQX) (10 $\mu \mathrm{mol} /$ $\mathrm{mL}$ ) were added to the external solution to block, respectively, N-methyl-D-aspartate (NMDA) and non-NMDA glutamate receptors. Conversely, to study the intrinsic properties of the neurons and evoked, spontaneous and miniature glutamate-mediated excitatory postsynaptic currents (eEPSCs, sEPSCs, mEPSCs), the recording pipettes were filled with internal solution of the following composition: (mM) $\mathrm{K}^{+}$-gluconate (125), $\mathrm{NaCl}$ (10),
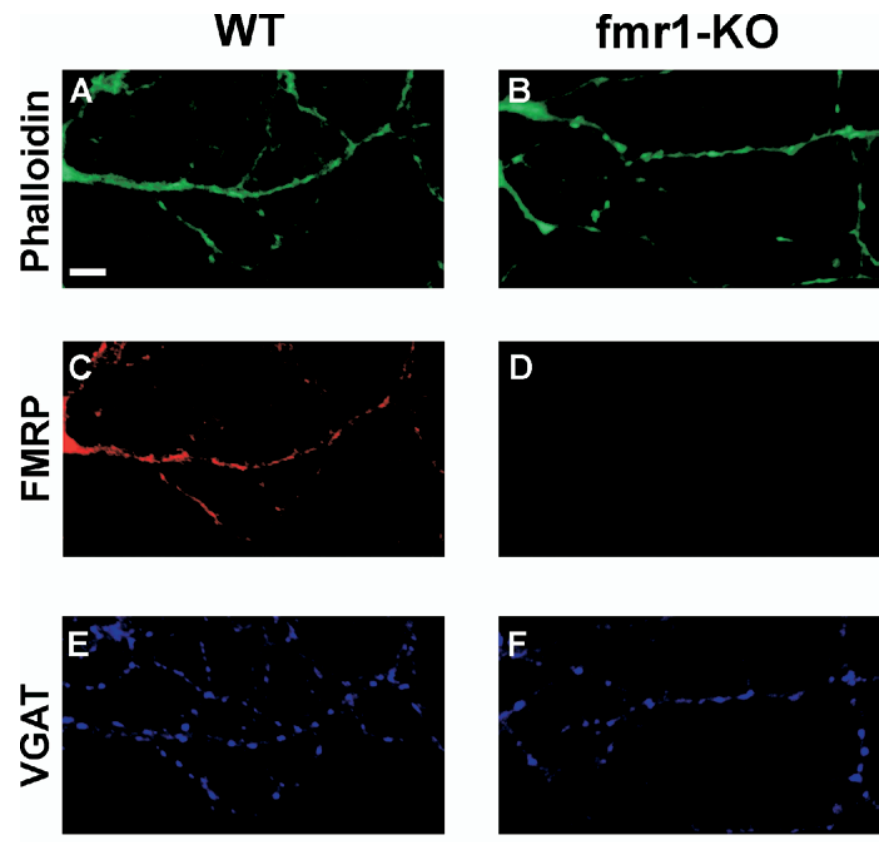

G

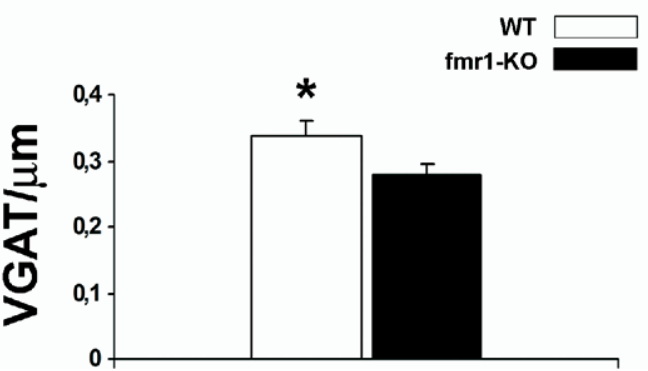

Figure 2. Distribution of $\gamma$-aminobutyric acid (GABA)-ergic synapses in wildtype (WT) and fmr1-knockout (KO) cultured striatal neurons. (A, B) Phalloidin staining in $\mathrm{WT}$ and fmr1-KO. (C, D) Fragile $X$ mental retardation protein (FMRP) immunofluorescence in WT and fmr1-KO. (E, F) Vesicular $\gamma$-hydroxybutyric acid (GABA) transporter (VGAT) immunofluorescence in WT and fmr1-KO. (G) Quantification of the VGAT puncta in WT and fmr1-KO cells. Bar $=10 \mu \mathrm{m}$.
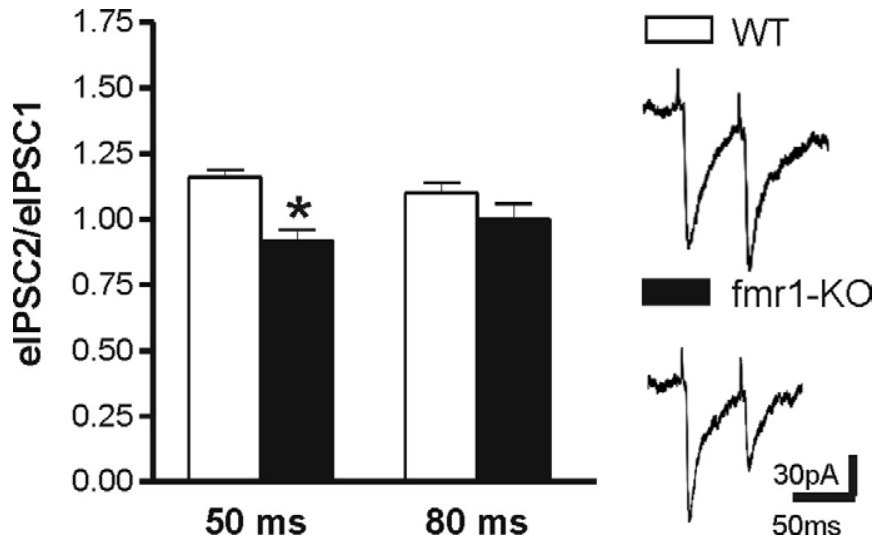

Figure 3. Paired-pulse ratio (PPR) in wildtype (WT) and fmr-knockout (KO) striatal neurons. The histogram shows that at 50-msec, but not at 80-msec, interstimulus intervals, the evoked spontaneous inhibitory postsynaptic currents (eIPSC) PPR in fmr1-KO mice is lower than in their WT counterparts. The right panel shows examples of PPR recordings at 50 -msec interstimulus intervals from WT (upper trace) and fmr1-KO (lower trace) striatal neurons.

$\mathrm{CaCl}_{2}$, (1.0), $\mathrm{MgCl}_{2}$ (2.0), 1,2-bis (2-aminophenoxy) ethaneN,N,N,N-tetraacetic acid (BAPTA; 0.5), HEPES (19), GTP (.3), Mg-ATP (1.0), adjusted to $\mathrm{pH} 7.3$ with potassium hydroxide (KOH). Bicuculline $(10 \mu \mathrm{mol} / \mathrm{mL})$ was added to the perfusing solution to block GABAA-mediated transmission.

Spontaneous and miniature synaptic events were stored by using P-CLAMP 9 (Axon Instruments) and analyzed offline on a personal computer with Mini Analysis 5.1 (Synaptosoft, Leonia, New Jersey) software. The detection threshold of spontaneous and miniature excitatory and inhibitory events was set at twice the baseline noise. The fact that no false events would be identified was confirmed by visual inspection for each experiment. Offline analysis was performed on spontaneous and miniature synaptic events recorded during fixed time epochs (2-3 min, 5-10 samplings), sampled every 2-3 minutes. Only cells that exhibited stable frequencies in control (less than $20 \%$ changes during the control samplings) were taken into account. For kinetic analysis, events with peak amplitude between 10 and $50 \mathrm{pA}$ were grouped, aligned by half-rise time, normalized by peak amplitude, and averaged to obtain rise times, decay times, and half widths. Events with complex peaks were eliminated.

Evoked synaptic events (eEPSCs, eIPSCs) were elicited at .1-Hz frequency by using bipolar electrodes located either in the white matter between the cortex and the striatum (to activate corticostriatal glutamatergic fibers) or within the striatum (to stimulate intrastriatal GABAergic terminals). P-CLAMP 9 was used to store the data. In distinct neurons, eEPSCs or eIPSCs of similar amplitude were obtained with highly variable intensities of stimulation, mainly depending on the distance between the stimulating and recording sites. eEPSCs normally ranged between 50 and 400 pA, and eIPSCs ranged between 30 and 200 pA. No gross difference in the intensity of stimulation required to obtain a given synaptic event was observed across genotypes.

For data presented as the mean \pm SEM, statistical analysis between two groups was performed using a paired or unpaired Student's $t$ test or Wilcoxon's test. Multiple comparisons were analyzed by one-way analysis of variance followed by Tukey's honest significant difference (HSD). The significance level was established at $p<.05$. To determine differences between two cumulative distributions, the Kolmogorov-Smirnov test was used. Throughout the text, $n$ refers to the number of cells. One to six 
neurons per animal were recorded. Each electrophysiologic measure in KO and WT mice was obtained by pooling data from at least six animals. Only one animal per day was used.

Drugs were applied by dissolving them to the desired final concentration in the bathing artificial cerebrospinal fluid (ACSF). The concentrations of the various drugs were chosen according to previous in vitro studies on corticostriatal brain slices $(33,34)$ and were as follows: CNQX (10 $\mu \mathrm{mol} / \mathrm{mL}), \mathrm{MK}-801(30 \mu \mathrm{mol} /$ $\mathrm{mL}$ ), tetrodotoxin (TTX, $1 \mu \mathrm{mol} / \mathrm{mL}$ ) (Tocris Cookson, Bristol, United Kingdom), bicuculline (10 $\mu \mathrm{mol} / \mathrm{mL})$, cadmium (200 $\mu \mathrm{mol} / \mathrm{mL}$ ), forskolin $(10 \mu \mathrm{mol} / \mathrm{mL}$ ) (Sigma, St. Louis, Missouri).

\section{Preparation of cRNA Probe}

RNA in situ hybridization was performed using antisense and sense probes for BC1 RNA. BC1 RNA was cloned into pGemTeasy vector starting from total brain RNA. Using the following primers: Mouse BC1 (U01310): -upstream 5'-GTT GGG GAT TTA GCT CAG TGG-3'; - downstream 5'-AGG TTG TGT GTG CCA GTT ACC-3'.

Linearization with SacII or SacI and transcription with SP6 or T7 polymerases leads to antisense or sense digoxygenin-labeled cRNA probes. Specificity of the probe was assessed performing Northern blot analysis on WT and BC1-KO mice (not shown).

\section{Tissue Preparation for Fluorescence In Situ Hybridization (FISH) and Immunofluorescence}

Mice were anesthetized and then perfused with $4 \%$ paraformaldehyde in $.1 \mathrm{~mol} / \mathrm{mL}$ phosphate buffered saline (PBS $\mathrm{pH}$ 7.4). Brains were removed and postfixed for 1 day in $4 \%$ paraformaldehyde/PBS. Brains were placed in 30\% sucrose in $.1 \mathrm{~mol} / \mathrm{mL}$ PBS until the brains sank and were then embedded in the optimal cutting temperature (OCT) compound (Sakura, supplied by Bio-Optica) and frozen on dry ice. Frozen brains were cryosectioned (20- $\mu \mathrm{m}$ thickness).

\section{FISH and Immunofluorescence on Striatal Tissue and Striatal Neurons}

Striatal neurons were fixed at room temperature for $15 \mathrm{~min}$ with $4 \%$ paraformaldheyde in PBS 1X. Immunofluorescence was performed as previously described (6). FISH and immunofluorescence on striatal tissue was performed as previously described (38)

\section{Antibodies}

Rabbit polyclonal anti-FMRP-rAM2 (1:300) (6), mouse monoclonal anti-Neurofilament-L (NF-L; 1:100, from Cell Signaling Technology, Danvers, Massachusetts), mouse monoclonal antivesicular GABA transporter (VGAT; 1:200, Synaptic System, Goettingen, Germany), Phalloidin-fluoresceine isothiocianate (1: 1000, SIGMA), anti-digoxigenin rhodamine conjugate (1:100, from Roche, Mannheim, Germany). Antimouse, antirabbit secondary antibodies conjugated to fluorophores (cyanine 2/3/5; 1:100, Jackson ImmunoResearch, West Grove, Pennsylvania).

\section{Counting of the VGAT Density}

Counting of VGAT, a reliable marker for GABAergic nerve terminals and GABAergic synapses (39) in WT and fmr1-KO cells (cultured striatal cells), was performed. The images were acquired using a confocal laser scanning microscope (TCS SP5, Leica Microsystem, Wetzlar, Germany). Quantitative analysis in triple-labelled material was performed in different cell cultures by counting the VGAT density of 15 cells for WT (64 dendrites with a total length of $9845 \mu \mathrm{m}$ contained 3210
A

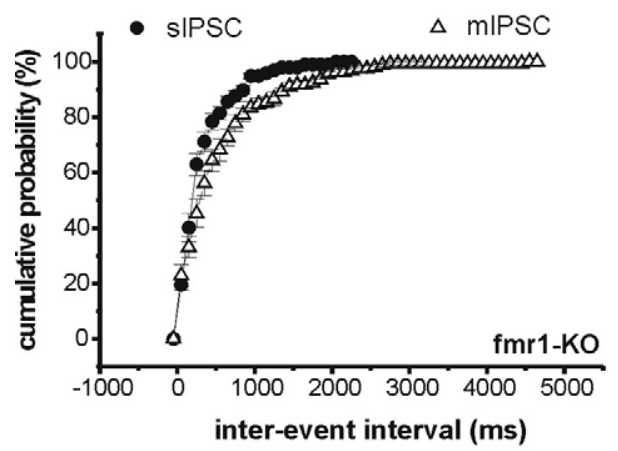

C
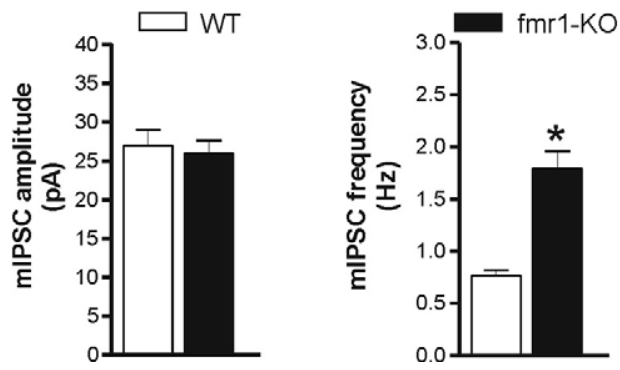

B

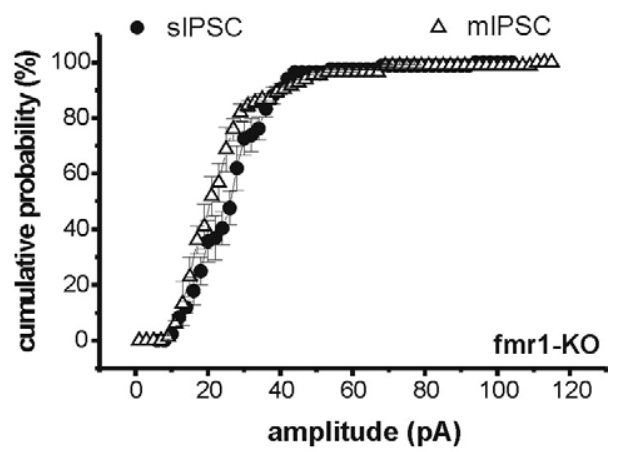

D

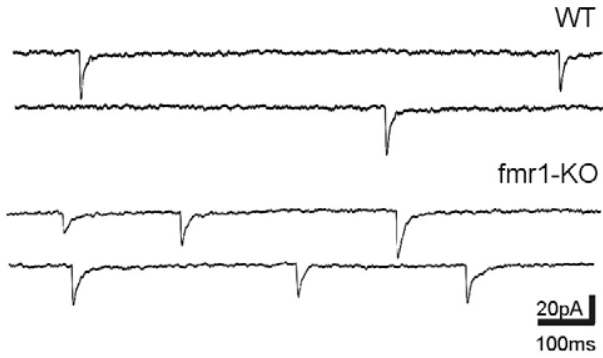

Figure 4. Properties of miniature inhibitory postsynaptic currents (mIPSCs) recorded from striatal neurons of wildtype (WT) and fmr1-knockout (KO) mice. (A, B) The graphs show that the blockade of voltage-dependent sodium channels by tetrodotoxin (TTX) changes the cumulative distribution of spontaneous IPSC (sIPSC) interevent interval (A) but not of sIPSC amplitude (B) in fmr1-KO mice. (C) The histograms show that absence of fragile X mental retardation protein (FMRP) remarkably increases the frequency of mIPSCs without altering the mean amplitude. (D) Examples of voltage-clamp recordings in the presence of TTX showing the increase of mIPSC frequency in fmr1-KO mice with respect to their WT controls. 
VGAT puncta) and 15 cells for fmr1-KO (55 dendrites with a total length of $7675 \mu \mathrm{m}$ contained 2180 VGAT puncta). One-way analysis of variance on the data were performed with the Tukey HSD comparison post hoc test.

\section{Results}

\section{Membrane Properties of Striatal Neurons}

Whole-cell patch clamp recordings were obtained from striatal spiny neurons identified by morphologic and electrophysiologic criteria. Striatal spiny neurons had significantly smaller somata than interneurons $(15-25 \mu \mathrm{m}$ vs. $30-40 \mu \mathrm{m})$ and displayed high resting membrane potential $(-81 \pm 4 \mathrm{mV})$, action potential discharge with little adaptation during depolarizing current pulses, and, in voltage-clamp mode, a typical currentvoltage relationship. These electrophysiologic properties were similar in fmr1-KO, BC1-KO, and fmr1-BC1-KO mice and the respective WT control mice and did not differ from those reported previously for spiny neurons of the mouse striatum (36-38) (not shown).

\section{Spontaneous GABAergic Activity in fmr1-KO Neurons}

As an indicator of the physiologic activity of GABA synapses, we measured sIPSCs in the striatum of WT and fmr1-KO mice. Electrophysiologic recordings with $\mathrm{CsCl}$-containing pipettes allowed detecting, at $-80 \mathrm{mV} \mathrm{HP}$ and in the presence of CNQX plus MK-801, spontaneous synaptic events that could be blocked in both genotypes by bicuculline ( $n=6$ for both groups). Most events had amplitudes ranging between 5 and $40 \mathrm{pA}$ and had kinetic properties (rise time, decay time constant, and half width) indistinguishable in the two genotypes ( $n \geq 20$ and $p>.05$ for the two experimental groups and for each parameter). The frequency of sIPSCs was conversely increased in fmr1-KO mice
( $n=28$ for both groups, $p<.001$ ), a result compatible with the idea that striatal GABAergic nerve terminals are disinhibited in this model of FXS (Figure 1).

\section{Density of GABA Synapses in fmr1-KO Striatal Neurons}

To assess whether the observed increase in GABA release probability could result from higher number of GABAergic synapses per cell in fmr1-KO mice, we investigated the presence of VGAT as a marker of GABAergic synapses (39). As shown in Figure 2, the amount of GABAergic synapses was decreased in the fmr1-KO cells $(p<.05)$

\section{Paired-Pulse Ratio in fmr1-KO Striatal Neurons}

The idea that the observed difference in sIPSC frequencies could result from genotypic differences in release probability was supported by paired-pulse experiments on eIPSCs. At 50msec interstimulus interval, in fact, fmr1-KO mice $(n=8)$ exhibited a lower paired-pulse ratio (PPR) compared with their WT counterparts ( $n=6, p<.01)$. This difference, however, was not evident when the two stimuli were delivered with an interstimulus interval of $80 \mathrm{msec}(n=6$ for WT and $n=8$ for fmr1-KO neurons, $p>.05$ ) (Figure 3 ).

\section{Miniature IPSCs in fmr1-KO Neurons}

To study further the physiologic properties of GABA synapses in WT and fmr1-KO striatal neurons, mIPSCs were recorded following blockade of voltage-dependent sodium channels with TTX ( $n=19$ for both genotypes). When compared with sIPSCs, mean frequency of mIPSCs was significantly lower in both genotypes, whereas mean amplitude was unchanged. Frequency, but not amplitude, of mIPSCs was higher than normal in fmr1-KOs $(p<.01)$, supporting the idea that FMRP modulates transmitter release through a presynaptic action and indepen-
A
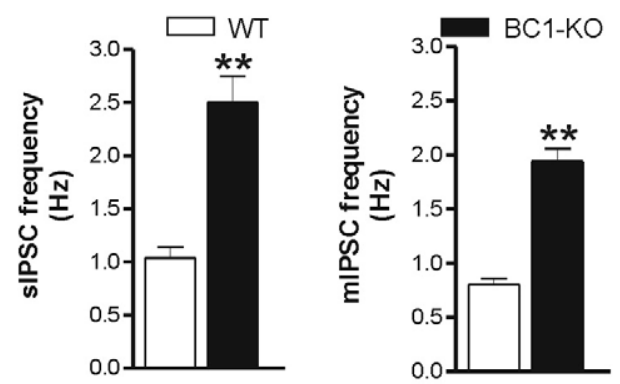

B

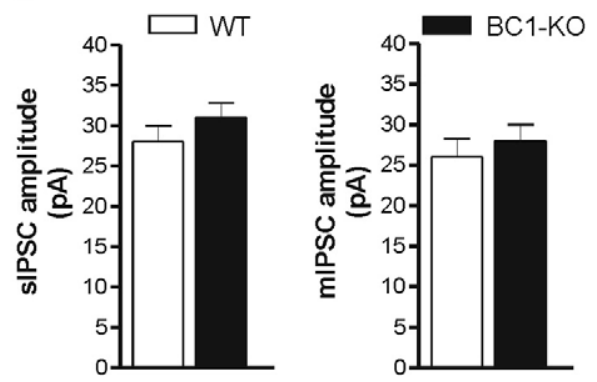

C

sIPSC

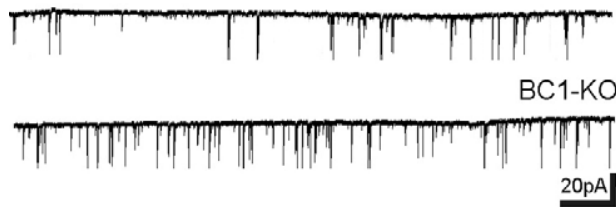

WT

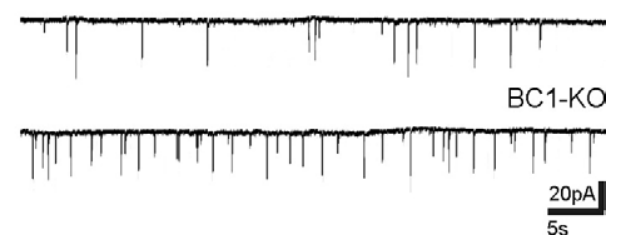

Figure 5. $\gamma$-aminobutyric acid (GABA) transmission in BC1-knockout (KO) striatal neurons. (A) The histograms show that the frequency of both spontaneous inhibitory postsynaptic currents (sIPSCs) and miniature IPSCS (mIPSCs) was higher in BC1-KO mice compared with their wildtype (WT) controls. (B) The histograms show that the amplitude of both sIPSCs and mIPSCs was similar in the two genotypes. (C) Examples of voltage-clamp recordings showing that inactivation of BC1 gene increased the frequency of sIPSCs. (D) Examples of voltage-clamp recordings in the presence of tetrodotoxin showing that BC1-KO increased the frequency of mIPSCs. 

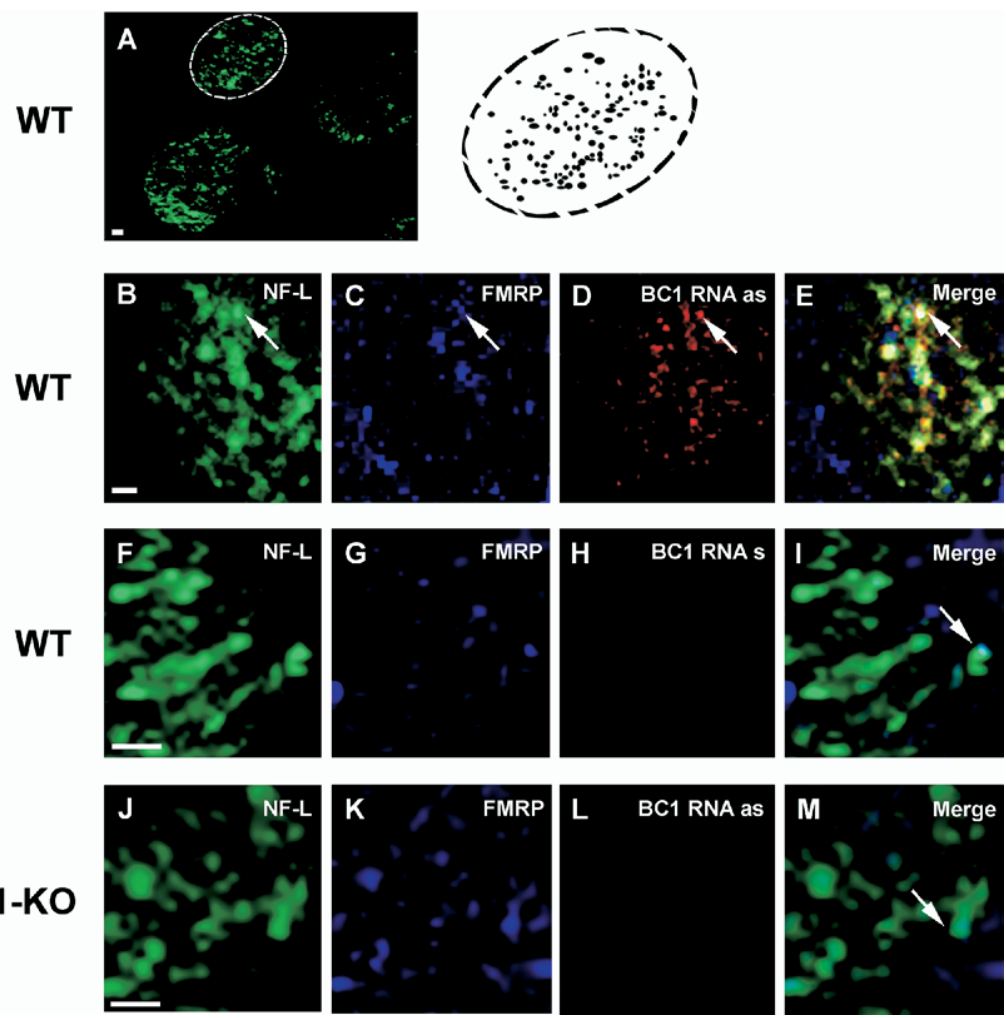

dently of action potential generation (Figure 4). In both WT and fmr1-KO mice, mIPSCs were insensitive to the application of cadmium (200 $\mu \mathrm{mol} / \mathrm{mL}, 10 \mathrm{~min}$ ), to block calcium channels ( $n=9$ for both genotypes, $p>.05$ ).

\section{GABA Transmission in BC1-KO Striatal Neurons}

Part of the physiologic activities of FMRP at synapses depends on the interaction of this protein with BC1 RNA, a small noncoding RNA (40). Thus, to test whether altered FMRP-BC1
Figure 7. $\gamma$-aminobutyric acid (GABA) transmission in double fmr1-brain cytoplasmic (BC1) knockout (KO) striatal neurons. (A) The histograms show that the frequency of spontaneous inhibitory postsynaptic currents (sIPSCs) (left panel) and miniature IPSCs (mIPSCs) (right panel) is higher in double fmr1-BC1-KO mice compared with their WT counterparts but similar compared with fmr1- and BC1-KO mice. (B) Lack of significant effects of double fmr1-BC1-KO, compared with isolated BC1-KO, on sIPSC interevent interval distribution.
A

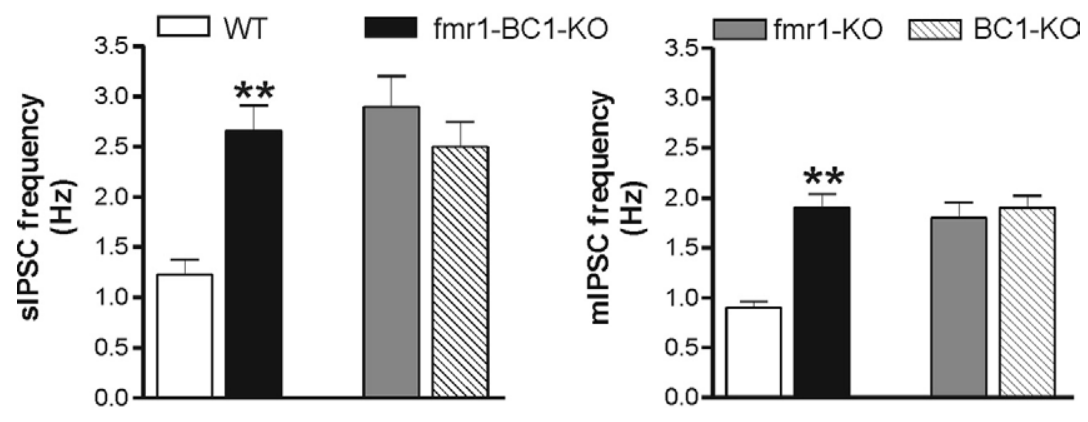

B

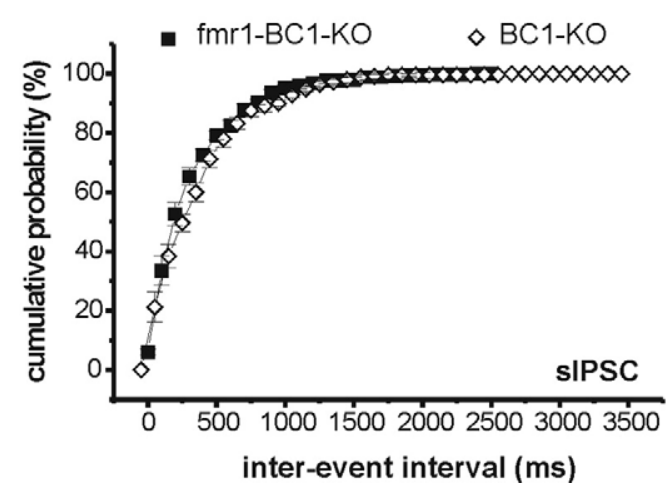


RNA interaction was involved in the abnormal GABA transmission seen in fmr1-KO neurons, we performed electrophysiologic recordings in mice lacking the $\mathrm{BC} 1 \mathrm{RNA}$. In $\mathrm{BC} 1-\mathrm{KO}$ striatal neurons, the frequency of sIPSCs ( $n \geq 26$ for both genotyes, $p<$ .001 ) and of mIPSCs ( $n \geq 16$ for both genotypes, $p<.001$ ) was higher than in controls and similar to those of FMRP KOs, whereas their amplitudes were unchanged $(p>.05$ for both sIPSCs and mIPSCs), as expected for a presynaptic alteration of GABA transmission in these mice (Figure 5).

\section{FMRP and BC1 RNA Partially Colocalize in Striatal Axonal Bundles}

GABAergic innervation of striatal neurons is entirely intrinsic, originating from axonal collaterals of projection cells ( $95 \%$ of striatal neuronal population) or from GABA interneurons (4146). Our electrophysiologic data pointed toward a presynaptic site for increased GABA transmission in mice lacking FMRP and BC1 RNA, implying that both molecules are present in axons of striatal cells. Thus, to verify the presence of FMRP and of BC1 RNA in axons of striatal neurons, we performed FISH conjugated to immunofluorescence in striatal slices. We observed that FMRP and BC1 RNA colocalize $(\leq 10 \%)$ within striatal axonal bundles (bundles are detected by the NF-L staining, see Figure 6A), as shown by their costaining with the NF-L, indicating a specific role for both molecules at presynaptic sites (Figure 6B-6E). Specificity of the $\mathrm{BC} 1$ detection is shown by the absence of signal by the use of BC1 RNA sense probe on WT tissue (Figure 6F-6I), as well as by the use of BC1 RNA antisense probe in BC1-KO striatal tissue (Figure 6J-6M).

\section{GABA Transmission in Double fmr1-BC1-KO Striatal Neurons}

The electrophysiologic experiments described show that BC1 RNA absence mimics the effects of genetic inactivation of FMRP on striatal GABA transmission. To confirm that the effects of the two genetic manipulations were mediated by the disruption of a common molecular cascade, we performed electrophysiologic experiments by using mice lacking both FMRP and BC1 RNA, to verify whether the synaptic effects of the two manipulations were additive. In these double mutants, the frequency of sIPSCs ( $n=$ $35)$ and of mIPSCs $(n=14)$ was significantly higher than in control mice ( $n=24$ for sIPSCs, $n=12$ for mIPSCs, $p<.001$ for both sIPSCs and mIPSCs) and remarkably similar to the frequencies recorded in isolated fmr1- and BC1-KOs ( $p=.55$ for sIPSCs and $p=.86$ for mIPSCs), indicating that the effects of $\mathrm{BC} 1$ absence occluded those of fmr1 disruption (Figure 7).

\section{Effects of Forskolin in WT and Mutant Mice}

The results obtained by using the double mutants are consistent with the idea that fmr1 and BC1 disruption interferes with a common signaling cascade to increase striatal GABA transmission. Saturation mechanisms of transmitter release, however, are an alternative explanation for these nonadditive effects. Thus, to address this possibility, we measured the effects of forskolin, an adenylyl cyclase activator known to increase GABA release from presynaptic terminals (47-49). Forskolin significantly increased the frequency of sIPSCs in WT mice $(n=6)$. Similar effects were observed in fmr1-KO $(n=6)$, BC1-KO $(n=7)$, and fmr1BC1-KO $(n=6)$ striatal neurons ( $p=.77$, comparing the effect in the three genotypes) (Figure 8).

\section{Spontaneous Glutamatergic Activity in fmr1-KO, BC1-KO, and fmr1-BC1-KO Striatal Neurons}

To see whether the synaptic abnormalities found in the three mutant mice were restricted to GABA-mediated transmission or

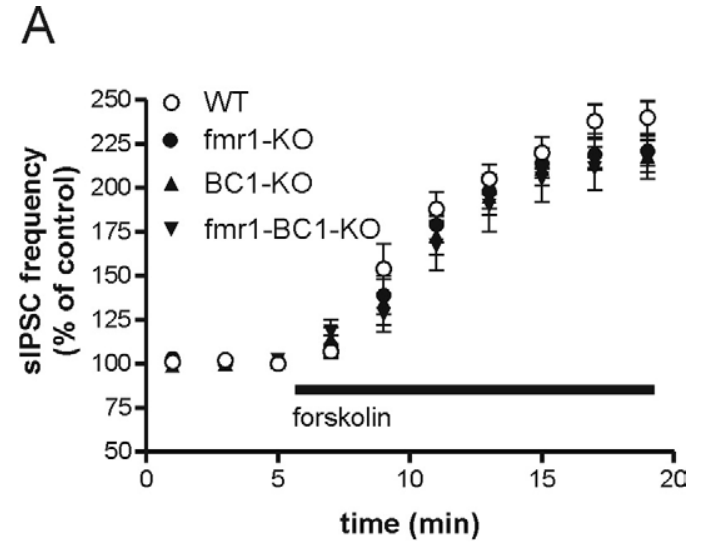

B
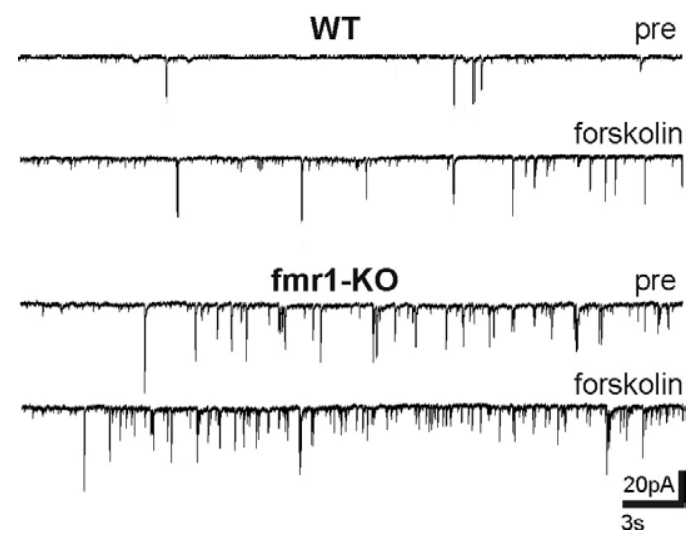

Figure 8. Effects of forskolin in wildtype (WT) and mutant mice. (A) The graph shows that forskolin enhances spontaneous inhibitory postsynaptic currents (sIPSCs) frequency in fmr1-KO mice, in brain cytoplasmic (BC1)-KO mice as well as in their WT counterparts. (B) Examples of voltage-clamp recordings showing the effects of forskolin on sIPSCs recorded from WT (upper traces) and fmr1 KO mice (lower traces).

also involved in glutamate-mediated transmission, we also recorded sEPSCs and mEPSCs. In fmr1-KO, BC1-KO, and fmr1BC1-KO striatal neurons, frequency and amplitude of sEPSCs were indistinguishable from the respective mEPSCs ( $n \geq 12$ and $p>.05$ for each genotype and both sEPSCs and mEPSCs) and were remarkably similar to sEPSCs $(n \geq 10)$ and mEPSCs $(n \geq 9)$ recorded from their WT counterparts $(p>.05)$. Also PPR of eEPSCs measured at 50-msec $(n \geq 9)$ and 80-msec $(n \geq 7)$ interstimulus intervals was unaltered in the three mutants (Figure 9).

\section{Discussion}

Reduced expression of FMRP in FXS patients causes a wide range of neuropsychiatric manifestations, which include mental retardation, hyperactivity, and autism (27, 50-52). Abnormal activity of striatal neurons and frontostriatal projections seem to play critical roles in FXS, as suggested by structural and functional neuroimaging studies. Accordingly, larger than normal caudate nucleus volumes have been found in human FXS brains, and a clear association between reduced FMRP expression, clinical severity, and morphological abnormalities of the basal ganglia has been detected (27-32). Furthermore, reduced activation of frontostriatal circuits has also been reported in these 
A

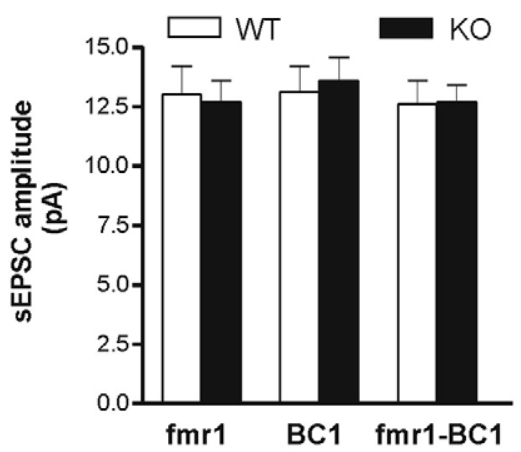

C

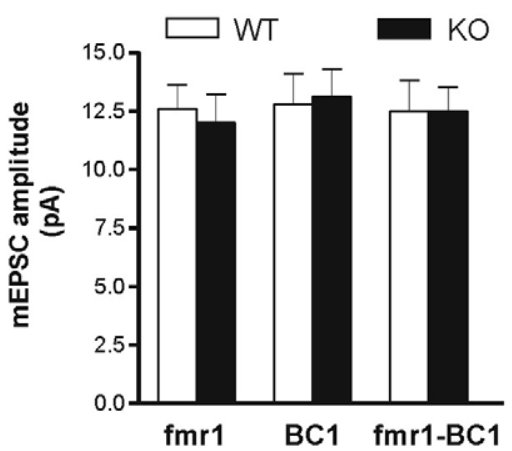

$E$

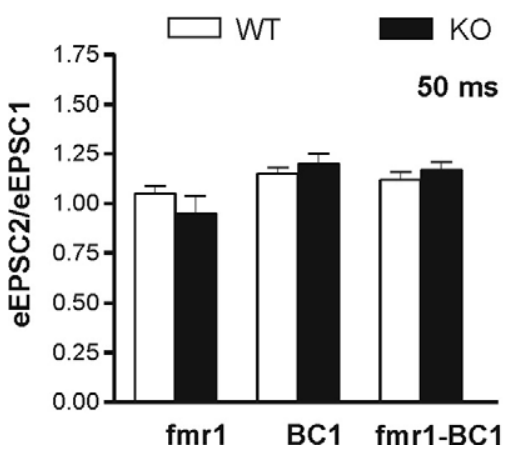

B

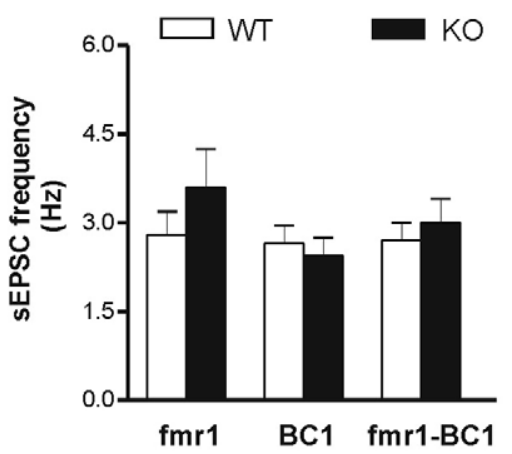

D

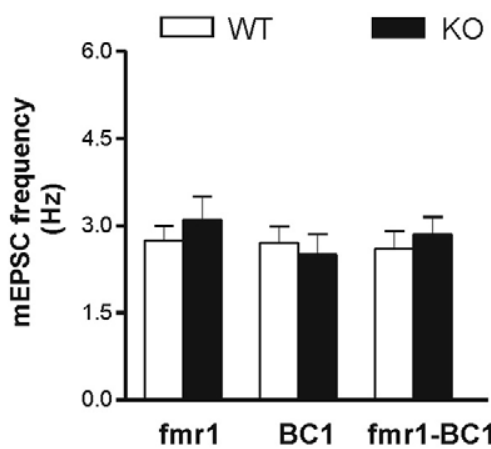

Figure 9. Glutamate transmission in corticostriatal slices from wildtype (WT) and mutant mice. (A, B) The histograms show that the amplitude $(\mathbf{A})$ and the frequency (B) of spontaneous evoked postsynaptic currents (sEPSCs) recorded from the three mutant mice are similar to those recorded from their respective WT counterparts. (C, D) The histograms show that the amplitude (C) and the frequency (D) of miniature EPSCs (mEPSC) recorded from the mutant mice are similar to those recorded from their respective WT counterparts. (E, F) The graphs show that eEPSC paired-pulse ratio (PPR) measured at both 50-msec (E) and 80-msec (F) interstimulus intervals is unaltered in the three mutants. patients, a finding also correlated with the level of FMRP expression (33).

In addition to its involvement in motor control, the striatum plays important roles in specific aspects of cognition and motivation, so that abnormal striatal function might account for the frequent observation of stereotypies, hyperactivity, and perseverative motor behavior in FXS patients (27,50-53). A further striking association between the fmr1 gene and basal ganglia deficits has recently emerged with the description of a new tremor-ataxia syndrome (FXTAS) characterized by both parkinsonism and hyperkinetic symptoms in carriers of premutation expansions of the gene $(54,55)$. Despite this recent evidence, synaptic transmission in the striatum of fmr1-KO mice has not been investigated before.

\section{FMRP in the Control of Striatal Synaptic Transmission}

FMRP functions as a platform for multiple interactions but the precise biological actions of this protein in neurons is still unknown. Of note, absence or mutation of this protein causes dendritic spine dysmorphogenesis and abnormal synaptic plasticity (2). Only glutamatergic pathways have been electrophysiologically and systematically investigated in fmr1-KO mice (16-19,56-59), although neurochemical and molecular studies suggested a parallel involvement of GABA system in these mutants. GABAA receptor expression is downregulated $(21,22,26)$ and cortical GABAergic interneurons are less abundant in fmr1-KO mice (25), suggesting reduced GABA signaling. Conversely, our data show that the frequency of GABAergic sIPSCs and of mIPSCs is enhanced in the striatum of FXS mice, even if GABAergic synapses appear to 
be reduced. A possible explanation for these discrepant results is that the downregulation of GABAA receptors and of GABA synapses reflects an adaptive mechanism aimed at countering the effects of abnormal GABA release in fmr1-KO mice. Notably, increased GABA synthesis and release has also been reported in previous studies in these mutants $(22,24)$.

This study is the first investigation of the synaptic properties of striatal neurons in fmr1-KO mice. It also represents the first work addressing the physiologic properties of GABA synapses in these mutants. Our results show that absence of FMRP is associated with normal glutamate-mediated transmission but abnormal GABA transmission in this brain area, an effect likely secondary to increased transmitter release from GABAergic nerve terminals. Accordingly, we have observed a selective increase of the frequency of GABA-mediated sIPSCs, whereas amplitude and kinetic properties of these events are unaltered. We have also observed reduced PPR of eIPSCs, in agreement with the idea that transmitter release probability of striatal GABAergic nerve terminals is higher in these mutants. The frequency of mIPSCs is also higher in fmr1-KO mice, indicating that abnormal action potential-independent release mediates, at least in part, the observed hyperactivity of GABA transmission.

The identification of FMRP in axons of striatal neurons provides a further support for the concept that this protein is involved in the control of GABA release within this nucleus. Indeed, the striatum is composed almost entirely of GABAergic cells, and almost all of GABA inputs to striatal cells arise from axon collateral of striatal neurons themselves or from striatal GABAergic interneurons (41-46). Dendrites and dendritic spines are the major locus of FMRP action (2), but recent evidence described the presence of this protein even along distal axon segments in the hippocampus $(5,6)$ and in peripheral neurons (7). The role of axonal FMRP is obscure, although its involvement in axonal growth and in synapse maturation during development has been proposed (5). Our data therefore provide the novel indication that FMRP may regulate transmitter release in mature GABAergic neurons.

\section{BC1 RNA in the Control of Striatal Synaptic Transmission}

FMRP is a RNA binding protein that interacts with several molecules $(2,4)$. The interaction with BC1 RNA seems to be crucial for its involvement in translation regulation because this small noncoding RNA has the potential to base pair to neuronal target mRNAs, connecting the mRNAs and FMRP $(14,40,60,61)$. BC1 RNA, as FMRP, is efficiently transported along dendrites and axons $(38,62-65)$ through a process requiring intact microtubules. In vitro, $\mathrm{BC} 1$ has been shown to act as translational repressor of chimeric mRNAs $(66,67)$. Although the involvement of BC1 RNA in the control of synaptic transmission has been postulated on the basis of its localization in neuritis, thus far no study addressed physiologically the synaptic effects of $\mathrm{BC} 1$ inactivation. Our findings show that this molecule is involved, as FMRP, in the regulation of striatal GABA-mediated transmission. Accordingly, we have replicated in BC1-KO mice the findings observed in fmr1 KOs: 1) selective increase of GABA-mediated SIPSC and mIPSC frequency and 2) normal glutamate-mediated transmission. Finally, we have also demonstrated the presence of BC1 RNA in axons of putative GABAergic neurons of the striatum, further confirming the role of this molecule in the control of GABA transmission.

\section{FMRP-BC1 RNA Interaction in the Control of Striatal Synaptic Transmission}

Considering the similar actions of FMRP and BC1 RNA on synaptic transmission and the molecular characterization of
FMRP-BC1 complex in regulating neuronal mRNA translation (12), one would expect that the synaptic defects observed in isolated fmr1- and BC1-KOs could be exacerbated when the two genes are simultaneously inactivated. The data obtained in the fmr1-BC1 double $\mathrm{KO}$ are suggestive of an in vivo interaction between the two molecules in the regulation of striatal synapses because we failed to observe additive alterations of GABA transmission in the fmr1-BC1 KO mice. This conclusion is also supported by the experiments with forskolin, which shows that in the three KO mice releasable pools of neurotransmitters are present in the GABAergic terminals, ruling out a saturation mechanism at the basis of the effects observed in fmr1-BC1 KO mice.

\section{Conclusions}

Emerging evidence indicates that correct synaptic transmission in central neurons depends on appropriate protein synthesis at synapses. Alterations of this process leads to FXS. Understanding the physiological role of FMRP and the synaptic defects associated with fmr1 disruption might be useful to design appropriate pharmacological interventions in FXS

*This work is an equal contribution between the labs of Drs. Bagni and Centonze.

This study was supported by grants from Ministero della Salute (Progetto Finalizzato) to DC; from European Community (Grant No. LSHM-CT-2004-511995, Synscaff) to PC; and from Ministero della Salute (FIRB), the Italian National Council for Research (Strategico "Genomica Funzionale"), and Telethon to $C B$. We thank Francesca Ferrari for preliminary experiments, Massimo Tolu for technical assistance, and Marco Molinari, Fulvio Florenzano, Maria Teresa Viscomi, Georgia Mandolesi for providing us with some of the antibodies used in this study. The authors are very grateful to Ben Oostra and Jürgen Brosius for the fmr1-KO and BC1-KO mice, respectively.

The authors have no conflict of interest of personal fees to declare.

1. Oberle I, Rousseau F, Heitz D, Kretz C, Devys D, Hanauer A, et al. (1991): Instability of a 550-base pair DNA segment and abnormal methylation in fragile X syndrome. Science 252:1097-1102.

2. Bagni C, Greenough WT (2005): From mRNP trafficking to spine dysmorphogenesis: The roots of fragile X syndrome. Nat Rev Neurosci 6:376387.

3. Kiebler MA, Bassell GJ (2006): Neuronal RNA granules: Movers and makers. Neuron 51:685-690.

4. Ule J, Darnell RB (2006): RNA binding proteins and the regulation of neuronal synaptic plasticity. Curr Opin Neurobiol 16:102-110.

5. Antar LN, Li C, Zhang H, Carroll RC, Bassell GJ (2006): Local functions for FMRP in axon growth cone motility and activity-dependent regulation of filopodia and spine synapses. Mol Cell Neurosci 32:37-48.

6. Ferrari F, Mercaldo V, Piccoli G, Sala C, Cannata S, Achsel T, Bagni C (2007): The fragile $X$ mental retardation protein-RNP granules show an mGluR-dependent localization in the post-synaptic spines. Mol Cell Neurosci 34:343-354.

7. Price TJ, Flores CM, Cervero F, Hargreaves KM (2006): The RNA binding and transport proteins staufen and fragile $X$ mental retardation protein are expressed by rat primary afferent neurons and localize to peripheral and central axons. Neuroscience 141:2107-2116.

8. Brown V, Jin P, Ceman S, Darnell JC, O'Donnell WT, Tenenbaum SA, et al. (2001): Microarray identification of FMRP-associated brain mRNAs and altered mRNA translational profiles in fragile X syndrome. Cell 107:477487.

9. Darnell JC, Jensen KB, Jin P, Brown V, Warren ST, Darnell RB (2001): Fragile $X$ mental retardation protein targets $G$ quartet mRNAs important for neuronal function. Cell 107:489-499.

10. Chen L, Yun SW, Seto J, Liu W, Toth M (2003): The fragile X mental retardation protein binds and regulates a novel class of mRNAs containing U rich target sequences. Neuroscience 120:1005-1017. 
11. Miyashiro KY, Beckel-Mitchener A, Purk TP, Becker KG, Barret T, Liu L, et al. (2003): RNA cargoes associating with FMRP reveal deficits in cellular functioning in Fmr1 null mice. Neuron 37:417-31.

12. Zalfa F, Giorgi M, Primerano B, Moro A, Di Penta A, Reis S, Oostra B, Bagni $C$ (2003): The fragile $X$ syndrome protein FMRP associates with BC1 RNA and regulates the translation of specific mRNAs at synapses. Cell 112: 317-327.

13. Zalfa F, Eleuteri B, Dickson KS, Mercaldo V, De Rubeis S, di Penta A, et al. (2007): A new function for the fragile $X$ mental retardation protein in regulation of PSD-95 mRNA stability. Nat Neurosci 10:578-587.

14. Zalfa F, Adinolfi S, Napoli I, Kuhn-Holsken E, Urlaub H, Achsel T, et al. (2005): Fragile X mental retardation protein (FMRP) binds specifically to the brain cytoplasmic RNAs BC1/BC200 via a novel RNA-binding motif. J Biol Chem 280:33403-33410.

15. Jin $P$, Alisch RS, Warren ST (2004): RNA and microRNAs in fragile $X$ mental retardation. Nat Cell Biol 6:1048-1053.

16. Huber KM, Gallagher SM, Warren ST, Bear MF (2002): Altered synaptic plasticity in a mouse model of fragile $\mathrm{X}$ mental retardation. Proc Natl Acad Sci U S A 99:7746-7750.

17. Koekkoek SK, Yamaguchi K, Milojkovic BA, Dortland BR, Ruigrok TJ, Maex R, et al. (2005): Deletion of FMR1 in Purkinje cells enhances parallel fiber LTD, enlarges spines, and attenuates cerebellar eyelid conditioning in Fragile $X$ syndrome. Neuron 47:339-352.

18. Larson J, Jessen RE, Kim D, Fine AK, du Hoffmann J (2005): Age-dependent and selective impairment of long-term potentiation in the anterior piriform cortex of mice lacking the fragile $\mathrm{X}$ mental retardation protein. J Neurosci 25:9460-9469.

19. Zhao MG, Toyoda H, Ko SW, Ding HK, Wu LJ, Zhuo M (2005): Deficits in trace fear memory and long-term potentiation in a mouse model for fragile X syndrome. J Neurosci 25:7385-7392.

20. D'Antuono M, Merlo D, Avoli M (2003): Involvement of cholinergic and gabaergic systems in the fragile $\mathrm{X}$ knockout mice. Neuroscience 119:9-13.

21. D'Hulst C, De Geest N, Reeve SP, Van Dam D, De Deyn PP, Hassan BA, Kooy RF (2006): Decreased expression of the GABAA receptor in fragile $X$ syndrome. Brain Res 1121:238-245.

22. El Idrissi A, Ding XH, Scalia J, Trenkner E, Brown WT, Dobkin C (2005): Decreased $G A B A(A)$ receptor expression in the seizure-prone fragile $X$ mouse. Neurosci Lett 377:141-146.

23. Gantois I, Vandesompele J, Speleman F, Reyniers E, D'Hooge R, Severijnen LA, et al. (2006): Expression profiling suggests underexpression of the $\operatorname{GABA}(\mathrm{A})$ receptor subunit delta in the fragile $X$ knockout mouse model. Neurobiol Dis 21:346-357.

24. Gruss M, Braun K (2004): Age- and region-specific imbalances of basal amino acids and monoamine metabolism in limbic regions of female Fmr1 knock-out mice. Neurochem Int 45:81-88.

25. Selby L, Zhang C, Sun QQ (2007): Major defects in neocortical GABAergic inhibitory circuits in mice lacking the fragile $\mathrm{X}$ mental retardation protein. Neurosci Lett 412:227-232.

26. D'Hulst C, Kooy RF (2007): The GABA(A) receptor: A novel target for treatment of fragile X? Trends Neurosci 30:425-431.

27. Reiss AL, Freund LS, Baumgardner TL, Abrams MT, Denckla MB (1995): Contribution of the FMR1 gene mutation to human intellectual dysfunction. Nat Genet 11:331-334.

28. Reiss AL, Lee J, Freund L (1994): Neuroanatomy of fragile X syndrome: The temporal lobe. Neurology 44:1317-1324.

29. Kates WR, Abrams MT, Kaufmann WE, Breiter SN, Reiss AL (1997): Reliability and validity of MRI measurement of the amygdala and hippocampus in children with fragile $\mathrm{X}$ syndrome. Psychiatry Res 75:31-48.

30. Mostofsky SH, Mazzocco MM, Aakalu G, Warsofsky IS, Denckla MB, Reiss AL (1998): Decreased cerebellar posterior vermis size in fragile $X$ syndrome: Correlation with neurocognitive performance. Neurology 50: 121-130.

31. Eliez S, Blasey CM, Freund LS, Hastie T, Reiss AL (2001): Brain anatomy, gender and IQ in children and adolescents with fragile $X$ syndrome. Brain 124:1610-1618.

32. Greicius MD (2003): Neuroimaging in developmental disorders. Curr Opin Neurol 16:143-146.

33. Menon V, Leroux J, White CD, Reiss AL (2004): Frontostriatal deficits in fragile $X$ syndrome: Relation to FMR1 gene expression. Proc Natl Acad Sci USA 101:3615-3620.
34. Bakker CE, Verheij C, Willemsen R, Vanderhelm R, Oerlemans F, Vermey $M$, et al. (1994): Fmr1 knockout mice: A model to study fragile $X$ mental retardation. Cell 78:23-33.

35. Skryabin BV, Sukonina V, Jordan U, Lewejohann L, Sachser N, Muslimov I, et al. (2003): Neuronal untranslated BC1 RNA: Targeted gene elimination in mice. Mol Cell Biol 23:6435-6441.

36. Centonze D, Grande C, Usiello A, Gubellini P, Erbs E, Martin AB, et al. (2003): Receptor subtypes involved in the presynaptic and postsynaptic actions of dopamine on striatal interneurons. J Neurosci 23:6245-6254.

37. Centonze D, Rossi S, Prosperetti C, Tscherter A, Bernardi G, Maccarrone M, Calabresi P (2005): Abnormal sensitivity to cannabinoid receptor stimulation might contribute to altered gamma-aminobutyric acid transmission in the striatum of R6/2 Huntington's disease mice. Biol Psychiatry 57:1583-1589.

38. Centonze D, Rossi S, Napoli I, Mercaldo V, Lacoux C, Ferrari F, et al. (2007): The brain cytoplasmic RNA BC1 regulates dopamine $D_{2}$ receptor-mediated transmission in the striatum. J Neurosci 27:8885-8892.

39. Tafoya LC, Mameli M, Miyashita T, Guzowski JF, Valenzuela CF, Wilson MC (2006): Expression and function of SNAP-25 as a universal SNARE component in GABAergic neurons. J Neurosci 26:7826-7838.

40. Zalfa F, Achsel T, Bagni C (2006): mRNPs, polysomes or granules: FMRP in neuronal protein synthesis. Curr Opin Neurobiol 16:265-269.

41. Wilson CJ, Groves PM (1980): Fine structure and synaptic connections of the common spiny neuron of the rat neostriatum: A study employing intracellular inject of horseradish peroxidase. J Comp Neurol 194:599-615.

42. Yung KK, Smith AD, Levey Al, Bolam JP (1996): Synaptic connections between spiny neurons of the direct and indirect pathways in the neostriatum of the rat: Evidence from dopamine receptor and neuropeptide immunostaining. Eur J Neurosci 8:861-869.

43. Bennett BD, Bolam JP (1994): Synaptic input and output of parvalbumin-immunoreactive neurons in the neostriatum of the rat. Neuroscience 62:707-719.

44. Plenz D, Kitai ST (1998): Up and down states in striatal medium spiny neurons simultaneously recorded with spontaneous activity in fastspiking interneurons studied in cortex-striatum-substantia nigra organotypic cultures. J Neurosci 18:266-283.

45. Koos T, Tepper JM (1999): Inhibitory control of neostriatal projection neurons by GABAergic interneurons. Nat Neurosci 2:467-472.

46. Gustafson N, Gireesh-Dharmaraj E, Czubayko U, Blackwell KT, Plenz D (2006): A comparative voltage and current-clamp analysis of feedback and feedforward synaptic transmission in the striatal microcircuit in vitro. J Neurophysiol 95:737-752.

47. Hack SP, Vaughan CW, Christie MJ (2003): Modulation of GABA release during morphine withdrawal in midbrain neurons in vitro. Neuropharmacology 45:575-584.

48. Murphy GJ, Isaacson JS (2003): Presynaptic cyclic nucleotide-gated ion channels modulate neurotransmission in the mammalian olfactory bulb. Neuron 37:639-647.

49. Harvey VL, Stephens GJ (2004): Mechanism of GABA receptor-mediated inhibition of spontaneous GABA release onto cerebellar Purkinje cells. Eur J Neurosci 20:684-700.

50. Bailey DB Jr, Mesibov GB, Hatton DD, Clark RD, Roberts JE, Mayhew L (1998): Autistic behavior in young boys with fragile X syndrome. J Autism Dev Disord 28:499-508.

51. Freund LS, Reiss AL (1991): Cognitive profiles associated with the fra $(X)$ syndrome in males and females. Am J Med Genet 38:542-547.

52. Hagerman RJ (2006): Lessons from fragile $X$ regarding neurobiology, autism, and neurodegeneration. J Dev Behav Pediatr 27:63-74.

53. Abrams MT, Reiss AL, Freund LS, Baumgardner TL, Chase GA, Denckla MB (1994): Molecular-neurobehavioral associations in females with the fragile X full mutation. Am J Med Genet 51:317-327.

54. Hagerman PJ, Hagerman RJ (2004): The fragile-X premutation: A maturing perspective. Am J Hum Genet 74:805-816.

55. Jacquemont $S$, Hagerman RJ, Hagerman PJ, Leehey MA (2007): Fragile-X syndrome and fragile $X$-associated tremor/ataxia syndrome: Two faces of FMR1. Lancet Neurol 6:45-55.

56. Chuang SC, Zhao W, Bauchwitz R, Yan Q, Bianchi R, Wong RK (2005): Prolonged epileptiform discharges induced by altered group I metabotropic glutamate receptor-mediated synaptic responses in hippocampal slices of a fragile X mouse model. J Neurosci 25:8048-8055.

57. Hou L, Antion MD, Hu D, Spencer CM, Paylor R, Klann E (2006): Dynamic translational and proteasomal regulation of fragile $\mathrm{X}$ mental retardation 
protein controls mGluR-dependent long-term depression. Neuron 51:441-454.

58. Nosyreva ED, Huber KM (2006): Metabotropic receptor-dependent long-term depression persists in the absence of protein synthesis in the mouse model of fragile X syndrome. J Neurophysiol 95:3291-3295.

59. Wilson BM, Cox CL (2007): Absence of metabotropic glutamate receptor-mediated plasticity in the neocortex of fragile X mice. Proc Natl Acad SciU S A 104:2454-2459.

60. Gabus C, Mazroui R, Tremblay S, Khandjian EW, Darlix JL (2004): The fragile $X$ mental retardation protein has nucleic acid chaperone properties. Nucleic Acids Res 32:2129-2137.

61. Johnson EM, Kinoshita Y, Weinreb DB, Wortman MJ, Simon R, Khalili K, et al. (2006): Role of Pur alpha in targeting mRNA to sites of translation in hippocampal neuronal dendrites. J Neurosci Res 83:929-943.

62. Brosius J, Tiedge H (2001): Neuronal BC1 RNA: Intracellular transport and activity-dependent modulation. Results Probl Cell Differ 34:129-138.
63. Cristofanilli M, lacoangeli A, Muslimov IA, Tiedge $H$ (2006): Neuronal BC1 RNA: Microtubule-dependent dendritic delivery. J Mol Biol 356:11181123.

64. Muslimov IA, Titmus M, Koenig E, Tiedge $\mathrm{H}$ (2002): Transport of neuronal BC1 RNA in Mauthner axons. J Neurosci 22:4293-4301.

65. Muslimov IA, Nimmrich V, Hernandez Al, Tcherepanov A, Sacktor TC, Tiedge $H$ (2004): Dendritic transport and localization of protein kinase Mzeta mRNA: Implications for molecular memory consolidation. J Biol Chem 279:52613-52622.

66. Kondrashov AV, Kiefmann M, Ebnet K, Khanam T, Muddashetty RS, Brosius J (2005): Inhibitory effect of naked neural BC1 RNA or BC200 RNA on eukaryotic in vitro translation systems is reversed by poly(A)-binding protein (PABP). J Mol Biol 353:88-103.

67. Wang $\mathrm{H}$, lacoangeli A, Popp S, Muslimov IA, Imataka H, Sonenberg N, et al. (2002): Dendritic BC1 RNA: Functional role in regulation of translation initiation. J Neurosci 22:10232-10241. 